\title{
Técnicas para formação de mudas de umbu-cajazeira por estaquia
}

\author{
Techniques for formation of umbu-cajazeira seedlings by cuttings \\ Técnicas para la formación de plántulas de umbu-cajazeira mediante esquejes
}

Recebido: 15/09/2021 | Revisado: 25/09/2021 | Aceito: 02/10/2021 | Publicado: 03/10/2021

\author{
Nouglas Veloso Barbosa Mendes \\ ORCID: https://orcid.org/0000-0003-4873-3206 \\ C \& N Serviços Agroambientais Ltda, Brasil \\ Agritech Semiárido Agricultura Ltda, Brasil \\ E-mail: nouglasmendes@ hotmail.com \\ Francisco Xavier de Souza \\ ORCID: https://orcid.org/0000-0002-7677-346X \\ Embrapa Agroindústria Tropical, Brasi \\ E-mail: xavier.souza@embrapa.br \\ Márcio Cleber de Medeiros Corrêa \\ ORCID: https://orcid.org/0000-0002-0702-4959 \\ Universidade Federal do Ceará, Brasil \\ E-mail: mcleber@ufc.br \\ Adroaldo Guimarães Rossetti \\ ORCID: https://orcid.org/0000-0002-0150-4089 \\ Embrapa Agroindústria Tropical, Brasil \\ E-mail: adroaldo.rossetti@embrapa.br \\ William Natale \\ ORCID: https://orcid.org/0000-0001-9572-4463 \\ Universidade Federal do Ceará, Brasil \\ E-mail: natale@ufc.br
}

\begin{abstract}
Resumo
A umbu-cajazeira necessita, ainda, de estudos que possam subsidiar o propagador e os interessados em disseminar clones dessa cultura no meio agrícola, pois se trata de frutífera com baixos percentuais de sementes viáveis, sendo a estaquia uma alternativa para a produção de mudas clonadas. Assim, objetivou-se avaliar o uso de indutores de enraizamento e estufins na formação de mudas clonadas de umbu-cajazeira por estacas. $\mathrm{O}$ experimento foi realizado no Campo Experimental da Embrapa, em Pacajus, Ceará, Brasil, em viveiro telado por sombrite® $50 \%$. Utilizou-se delineamento inteiramente casualizado com seis tratamentos, em esquema fatorial $(3 \times 2)$ : indutores de enraizamento Sela Gel®, Radimax ${ }^{\circledR}$ e sem indutor, com e sem estufim, com quatro repetições de dez estacas/parcela. O plantio foi em vasos de polietileno de $6 \mathrm{~L}$, preenchidos com substrato composto por vermiculita, bagana de carnaúba, pó de coco e cascas de arroz carbonizadas $(2: 1: 1: 1 \mathrm{v} / \mathrm{v})$. As regas foram por subirrigação realizadas duas vezes por semana, sendo que a metade das estacas permaneceram sob estufins por 44 dias de um total de 80 dias do período experimental. As estacas tratadas com Sela Gel® diferiram significativamente das demais, para todas as variáveis avaliadas, apresentando 51,25\% de enraizamento, 30\% de mudas aptas ao plantio e média de 29,50 folíolos por muda. As estacas tratadas com Radimax ${ }^{\circledR}$ apresentaram baixo percentual de enraizamento $(22,50 \%)$ e, também, de mudas aptas ao plantio $(7,50 \%)$. O uso de estufim favoreceu a maior formação de calos nas estacas.
\end{abstract}

Palavras-chave: Spondias; Propagação vegetativa; Ambiente protegido; Estufim.

\begin{abstract}
The umbu-cajazeira still needs studies that can subsidize the propagator and those interested in disseminating clones of this culture in the agricultural environment, as it is a fruitful with a low percentage of viable seeds the and cuttings are an alternative for the production of cloned seedlings. Thus, the objective was to evaluate the use of rooting inducers and mini-greenhouses in the formation of cloned umbu-cajazeira seedlings by cutting. The experiment was carried out at the Embrapa Experimental Field, in Pacajus, Ceará, Brazil, in a nursery with a 50\% sombrite ${ }^{\circledR}$. A completely casualized design was used with six treatments, in a factorial scheme $(3 \times 2)$ : rooting inducers Sela Gel ${ }^{\circledR}$, Radimax $^{\circledR}$ and without inducer, with and without mini-greenhouses, with four replications of ten cuttings/plot. The planting was in $6 \mathrm{~L}$ polyethylene pots, filled with a substrate composed of vermiculite, carnauba bagana, coconut powder and carbonized rice husks $(2: 1: 1: 1 \mathrm{v} / \mathrm{v})$. The irrigation was carried out by sub-irrigation carried out twice a week, with half of the cuttings remained in mini-greenhouses for 44 days out of a total of 80 days of the experimental period. The cuttings treated with Sela $\mathrm{Gel}^{\circledR}$ differed significantly from the others, for all evaluated variables, presenting $51.25 \%$ of rooting, 30\% of seedlings suitable for planting and an average of 29.50 leaflets per seedling. The cuttings treated with Radimax ${ }^{\circledR}$ showed a low percentage of rooting $(22.50 \%)$ and, also, seedlings suitable for planting $(7.50 \%)$. The use of mini-greenhouses favored greater callus formation in the cuttings.
\end{abstract}

Keywords: Spondias; Vegetative propagation; Protected environment; Mini-greenhouses. 


\begin{abstract}
o
La umbu-cajazeira aún necesita estudios que puedan subsidiar al propagador y a los interesados en difundir clones de este cultivo en el medio agrícola, ya que es una fructífero con un bajo porcentaje de semillas viables, siendo el esquejes son una alternativa para la producción de plántulas clonados. Así, el objetivo fue evaluar el uso de inductores de enraizamiento y mini-invernaderos en la formación de plántulas clonadas de umbu-cajazeira por esqueje. El experimento se realizó en el Campo Experimental Embrapa, en Pacajus, Ceará, Brasil, en un vivero con un 50\% de sombrite $^{\circledR}$. Se utilizó un diseño completamente casualizado con seis tratamientos, en esquema factorial (3x2): inductores de enraizamiento Sela Gel ${ }^{\circledR}$, $\operatorname{Radimax}^{\circledR}$ y sin inductor, con y sin mini-invernaderos, con cuatro repeticiones de diez esquejes/parcela. La siembra se realizó en macetas de polietileno de $6 \mathrm{~L}$, rellenas con un sustrato compuesto de vermiculita, carnauba bagana, coco en polvo y cascarilla de arroz carbonizada (2:1:1:1 v/v). El riego se realizó mediante sub-riego realizado dos veces por semana, siendo que la mitad de los esquejes permanecieron en miniinvernaderos durante 44 días de un total de 80 días del período experimental. Los esquejes tratados con Sela Gel ${ }^{\circledR}$ difirieron significativamente de los demás, para todas las variables evaluadas, presentando 51,25\% de enraizamiento, $30 \%$ de plántulas aptas para plantar y una media de 29,50 folíolos por plántula. Los esquejes tratados con Radimax ${ }^{\circledR}$ mostraron un bajo porcentaje de enraizamiento $(22,50 \%)$ y, también, de plántulas aptas para plantar (7,50\%). El uso de mini-invernaderos favoreció los mayor formación de callos en los esquejes.
\end{abstract}

Palavras clave: Spondias; Propagación vegetativa; Ambiente protegido; Mini-invernaderos.

\title{
1. Introdução
}

A umbu-cajazeira (Spondias sp.) é planta frutífera, xerófita, cujos frutos possuem diferentes nomes comuns: umbu-cajá, cajá-umbu, cajarana, cajá-redondo, cajá-do-sertão, cajá-amarelo, cajá-doce, cajazinha e umbu. Em revisão do gênero Spondias, Mitchell e Daly (2015) afirmam que a umbu-cajazeira pertence à família Anacardiaceae e a consideram uma variante do umbuzeiro (Spondias tuberosa Arruda). Contudo, Machado, Carvalho e Van den Berg (2015), após estudos moleculares, morfométricos, morfológicos e de divergência temporal, concluíram que a planta é uma linhagem distinta do umbuzeiro e a nominaram de Spondias bahiensis (Carvalho, Van den Berg \& Machado).

A planta tem origem desconhecida e está dispersa pelo Semiárido do Nordeste brasileiro. Exemplares são encontrados tanto nas cidades quanto nas zonas rurais, principalmente em quintais, onde existem plantas centenárias muito produtivas. A produtividade dessas plantas pode atingir mais de $1.500 \mathrm{Kg}$ de fruto por safra, abastecendo anualmente as centrais de abastecimento e as indústrias de processamento de polpa da região Nordeste (Souza, Porto Filho, \& Mendes, 2020).

Segundo Souza et al. (2020), as umbu-cajazeiras raramente produzem sementes viáveis; por isso, torna-se quase obrigatória a propagação por via vegetativa, sendo a estaquia, com o uso de estacões de caule (aproximadamente 2,0 metros de comprimento), o método tradicionalmente empregado. Porém, essa técnica exige a realização de poda drástica na planta matriz, que além de agredir e prejudicar o seu desenvolvimento, apresenta baixo rendimento no enraizamento desse tipo de estaca. Na estaquia de umbu-cajazeira, são relatados índices de $25 \%$ a $35 \%$, comprovando que a planta é de difícil enraizamento (Façanha, 1997; Lopes, 1997; Bastos, 2010; Vieira, Alves, Souza, Batista, \& Batista, 2020). Daí a necessidade da realização de pesquisas, na busca de técnicas para viabilizar a propagação por estaquia, com o uso de estacas de tamanhos menores e com altas taxas de regeneração de clones.

A coleta de propágulos de espécies de difícil enraizamento deve ser realizada no período de repouso vegetativo (Paiva \& Gomes, 1995). Para Spondias, Souza e Costa (2010) recomendam a retirada de material propagativo no final dessa fase, ou seja, quando as matrizes estão sem folhas e os ramos com gemas túrgidas. Segundo Hartmann, Kester, Davies Jr. e Geneve (2011), são vários os fatores exógenos e endógenos envolvidos na capacidade de enraizamento de estacas. Esses autores afirmam, também, que as auxinas são usadas para estimular a divisão celular, a formação de calo e a emissão de raízes adventícias em estacas de várias plantas. As formulações convencionais de auxinas comercializadas são geralmente concentradas, necessitando de diluição em laboratório (Barroso et al., 2018), o que pode dificultar o uso pelos viveiristas. Atualmente, lojas de produtos agropecuários já comercializam indutores de enraizamento prontos para uso, facilitando a 
aplicação, como é o caso dos produtos Sela Gel $^{\circledR}$ e Radimax ${ }^{\circledR}$; estes produtos já possuem formulação e indicação de dose de acordo com o fabricante (Barroso et al., 2018).

O ambiente para enraizamento também pode influenciar as respostas das plantas, e está associado às instalações do viveiro. Fachinello, Hoffmann, Nachtgal e Kersten (2005) recomendam instalações especiais para viveiros sob telados e, dentro deles, o uso de estufins. Os estufins são miniestufas, com maior versatilidade, menor tamanho e custo, podendo ser estruturas permanentes ou provisórias, devendo ser instaladas em locais com bastante sombra para evitar altas temperaturas e a perda de umidade pelas plantas (Pereira, Aguilar, Sodré, Pasqual, \& Mendes, 2002). O controle da umidade no ambiente de enraizamento pode proporcionar melhoria no índice de sobrevivência e enraizamento das estacas (Pio et al., 2006). Nas estacas de umbu-cajazeira é de suma importância a manutenção da umidade no tecido vegetal, ainda que se trate de uma espécie rústica e bastante propensa a emitir brotações.

Diante do exposto, objetivou-se avaliar o uso de indutores de enraizamento e estufins na formação de mudas umbucajazeira por estacas.

\section{Metodologia}

O experimento foi realizado no Campo Experimental da Embrapa Agroindústria Tropical, localizado na margem da CE-253 km 42, em Pacajus, Ceará, Brasil. O clima, segundo a classificação de Köppen, é do tipo Aw, com precipitação média anual de $931 \mathrm{~mm}$, estação chuvosa de janeiro a junho e outra seca no restante do ano; a umidade relativa média do ar é de 77\%, a temperatura média anual é de $26,3^{\circ} \mathrm{C}$ e a velocidade média do vento é de $1 \mathrm{~m} / \mathrm{s}$ (Aguiar, Lima, Barreto Júnior, Carneiro, \& Lima, 2002). O período experimental foi de quatro meses e caracterizou-se pela temperatura média de $27,02^{\circ} \mathrm{C}$ e umidade relativa média de $68,13 \%$ (Figura 1 ).

Figura 1. Valores médios da temperatura máxima, média e mínima, e da umidade relativa do ar durante o período experimental, Pacajus, CE.

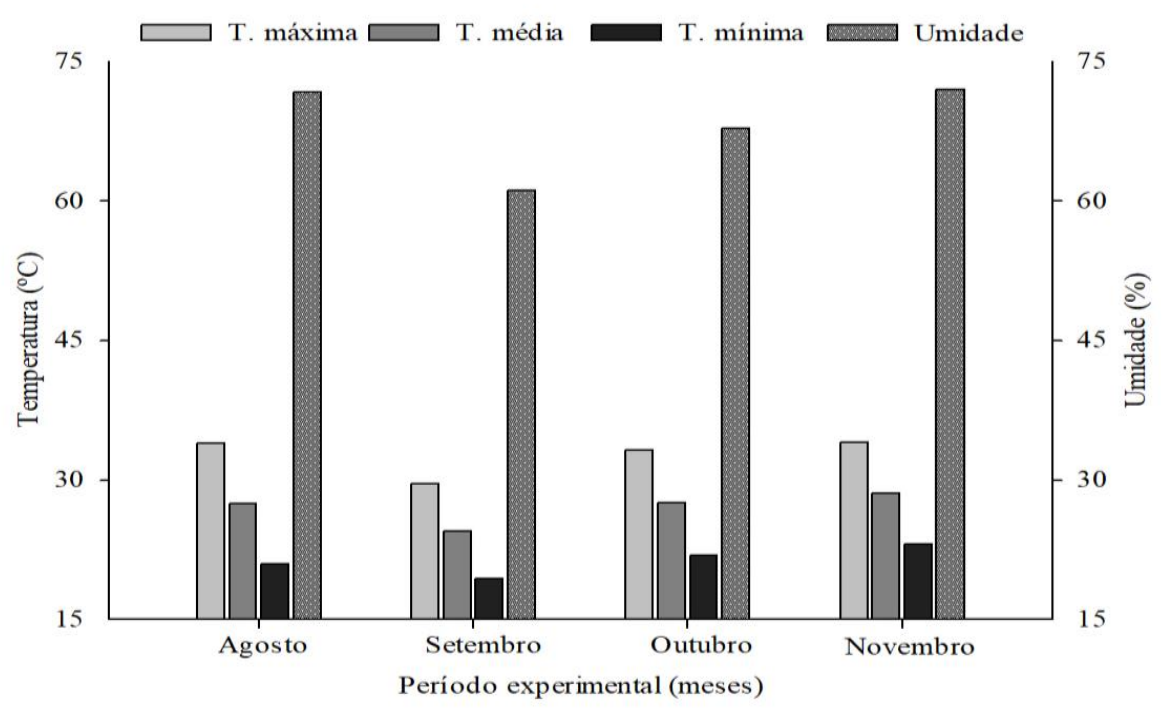

Fonte: Autores.

Os tratamentos foram distribuídos em DIC, em fatorial (3×2), correspondente à combinação da aplicação de indutores de enraizamento na base das estacas (sem indutor, Sela Gel $^{\circledR}$ e Radimax ${ }^{\circledR}$ ), e dois tipos de ambientes (com e sem estufim). Foram utilizadas quatro repetições e dez estacas/parcela, perfazendo 240 estacas. Segundo o fabricante, o Sela $\mathrm{Gel}^{\circledR}$ é um produto formulado para evitar a embolia das estacas após o corte, formando uma película protetora para evitar a entrada de ar; 
além de promover o enraizamento por meio da concentração de AIB $3.000 \mathrm{mg} \cdot \mathrm{L}^{-1}$ (Ecoplanet, 2012). O Radimax ${ }^{\circledR}$, por sua vez, é um produto desenvolvido para fertilizar e melhorar o enraizamento, baseando-se na mistura de N-P-K com aminoácidos específicos e oligoelementos que promovem o desenvolvimento das raízes (Coda, 2016).

Os propágulos foram retirados de ramos lenhosos de uma planta adulta de umbu-cajazeira, centenária, cultivada na Fazenda Raposa, pertencente à Universidade Federal do Ceará, em Maracanaú, CE. Depois de retirados, os propágulos foram transportados para o viveiro, onde se prepararam as estacas com $20 \mathrm{~cm}$ de comprimento, com médias de 6,2 $\mathrm{mm}$ de diâmetro e 6,6 gemas por estaca. As estacas foram imersas por 4 minutos em uma solução de hipoclorito de sódio a 0,5\%. Em seguida, foram separadas as parcelas: nas estacas sem tratamento (testemunhas) não houve aplicação de indutor de enraizamento; nas estacas que receberam indutor de enraizamento foram feitos ferimentos (dois riscos com a ponta do canivete cada um em lados opostos) de 3,0 cm de comprimento, na base das estacas, conforme recomendação de Mendes, Souza, Rossetti, Natale e Corrêa (2019). Logo após a realização dos ferimentos, o Sela $\mathrm{Gel}^{\circledR}$ foi aplicado por pincelamento e o Radimax ${ }^{\circledR}$ por imersão em uma solução de $10 \mathrm{~mL}$ do produto por litro d'água, durante 10 minutos (Figura 2).

Figura 2. Estacas retiradas de propágulos lenhosos de umbu-cajazeira (A), ferimentos (dois riscos em lados opostos) na base da estaca (B), aplicação por pincelamento do Sela $\mathrm{Gel}^{\circledR}$ no ferimento (C) e aplicação por imersão de solução do $\operatorname{Radimax}^{\circledR}$ no ferimento (D). Pacajus, CE.
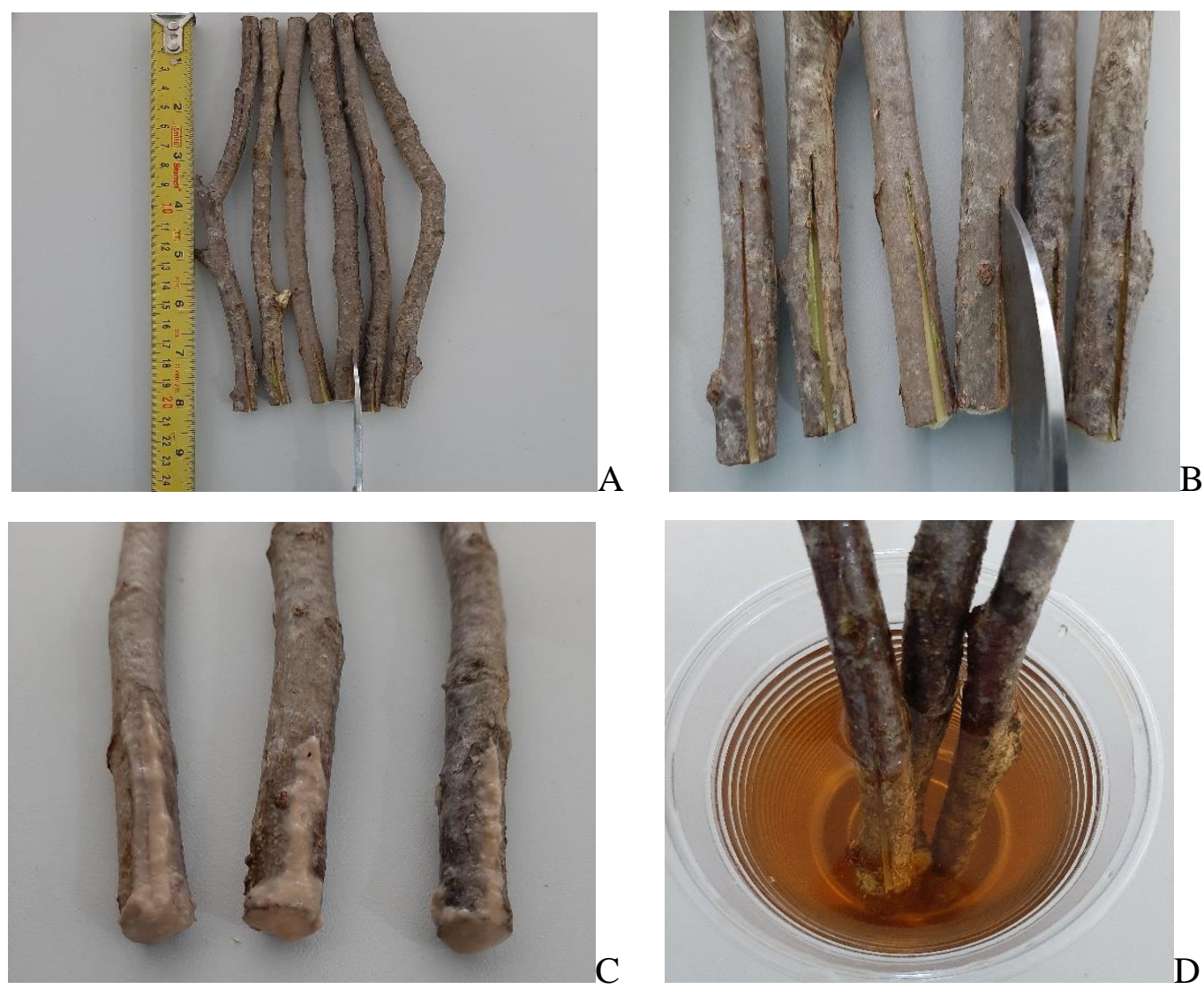

Fonte: Autores.

As estacas foram plantadas 10 minutos após a aplicação dos indutores de enraizamento, em vasos de plástico pretos, com capacidade para 6 litros. O substrato utilizado foi composto pela combinação de vermiculita, pó de casca de coco, bagana de carnaúba e casca de arroz carbonizada $(2: 1: 1: 1, \mathrm{v} / \mathrm{v})$. 
Os vasos, logo após o plantio das estacas, foram colocados sobre pratos e distribuídos aleatoriamente em cima de bancada de madeira, sendo mantidos sob telado de sombrite ${ }^{\circledR}$ com retenção de $50 \%$ da radiação solar. Metade dos vasos do experimento ficaram sob os estufins feitos com sacos plásticos transparentes de $40 \mathrm{~cm}$ x $60 \mathrm{~cm}$, colocados sobre hastes de arame fixadas nos vasos e amarrados na base com ligas de borracha (Figura 3). As regas foram realizadas por subirrigação duas vezes por semana, colocando-se água dentro dos pratos sob os vasos (capacidade 1,1 L de água), forçando a absorção por capilaridade para manter a umidade uniforme. Os estufins foram retirados de todos os vasos aos 44 dias após o plantio das estacas, pois as brotações e folíolos estavam em contato com o plástico.

Figura 3. Vasos com ou sem estufim, contendo estacas de ramo lenhoso de umbu-cajazeira. Pacajus, CE.

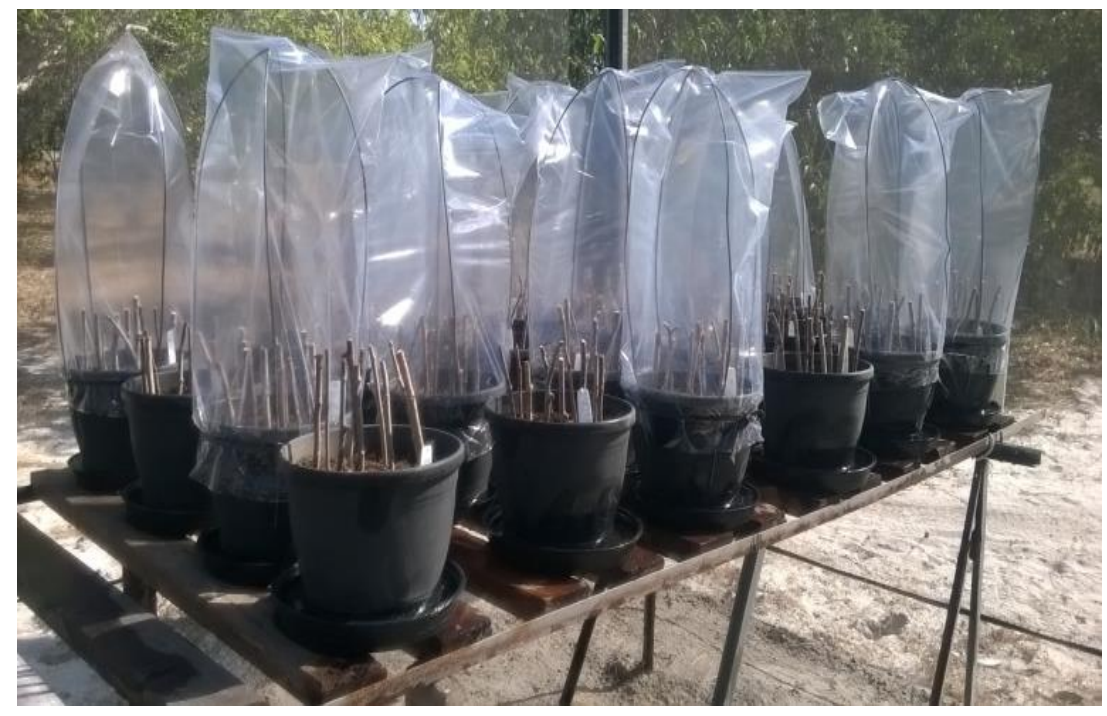

Fonte: Autores.

A cada 15 dias eram feitas avaliações para quantificar a brotação e o número de folíolos presentes nas folhas e retirar panículas que sugiram. As avaliações finais foram realizadas aos 80 dias após o plantio das estacas, quando se registrou as percentagens de estacas com calo, de estacas enraizadas, de mudas aptas para o plantio (mudas vigorosas com mais de quatro folhas desenvolvidas) e número de folíolos.

Para as análises estatísticas utilizando-se o software Statistical Analysis System - SAS ${ }^{\circledR}$ versão 9.2 (SAS Institute, 2009). Para a análise de variância os dados foram transformados em $\sqrt{x+1}$ (Steel \& Torrie, 1980) e as médias dos tratamentos comparadas pelo teste de REGWQ a 5\% de probabilidade.

\section{Resultados e Discussão}

O efeito dos indutores de enraizamento foi significativo para todas as variáveis analisadas (Tabela 1). Por sua vez, o uso ou não do estufim afetou significativamente apenas a emissão de calo. Pelo teste $\mathrm{F}$ não houve efeito da interação entre indutor de enraizamento e uso do estufim para qualquer das variáveis avaliadas. 
Tabela 1. Análise de variância do percentual de calo, de enraizamento, de mudas aptas ao plantio e do número de folíolos em mudas formadas por estacas de ramo lenhoso de umbu-cajazeira. Pacajus, CE.

\begin{tabular}{|c|c|c|c|c|c|c|c|c|c|}
\hline \multirow{2}{*}{ F. de Variação } & \multirow{2}{*}{ GL } & \multicolumn{2}{|c|}{$\begin{array}{l}\text { Calo } \\
(\%)\end{array}$} & \multicolumn{2}{|c|}{$\begin{array}{c}\text { Enraizamento } \\
(\%)\end{array}$} & \multicolumn{2}{|c|}{$\begin{array}{c}\text { Mudas aptas ao } \\
\text { plantio }(\%)\end{array}$} & \multicolumn{2}{|c|}{ Número de folíolos } \\
\hline & & QM & $\operatorname{Pr}>F^{1}$ & QM & $\operatorname{Pr}>\mathrm{F}^{1}$ & QM & $\operatorname{Pr}>\mathrm{F}^{1}$ & QM & $\operatorname{Pr}>F^{1}$ \\
\hline Enraizador (E1) & 2 & 0,1437 & 0,0235 & 0,5283 & $<0,0001$ & 0,2195 & $<0,0001$ & 120,0228 & $<0,0001$ \\
\hline Estufim (E2) & 1 & 0,2316 & 0,0139 & 0,0001 & 1,0000 & 0,0007 & 0,8530 & 0,0186 & 0,9626 \\
\hline Inter. (E1*E2) & 2 & 0,0150 & 0,6719 & 0,0279 & 0,4152 & 0,0350 & 0,1874 & 15,6380 & 0,1589 \\
\hline Resíduo & 234 & 0,0377 & - & 0,0316 & - & 0,0208 & - & 8,4335 & - \\
\hline $\mathrm{CV}(\%)$ & & \multicolumn{2}{|c|}{15,29} & \multicolumn{2}{|c|}{15,86} & \multicolumn{2}{|c|}{13,54} & \multicolumn{2}{|c|}{101,69} \\
\hline Média geral & & \multicolumn{2}{|c|}{65,00} & \multicolumn{2}{|c|}{29,17} & \multicolumn{2}{|c|}{15,42} & \multicolumn{2}{|c|}{16,51} \\
\hline
\end{tabular}

Dados transformados por $\sqrt{ } \mathrm{X}+1 .{ }^{1}$ Nível de significância do teste $\mathrm{F}$.

Fonte: Autores.

Observou-se, ainda, que os coeficientes de variação oscilaram entre 13,54\% e 101,69\%, indicando alta dispersão relativa dos dados em relação às médias, principalmente do número de folíolos. Essa alta dispersão deveu-se, provavelmente, aos efeitos dos tratamentos e dos propágulos, que apesar de retirados de uma única planta-matriz possuíam, possivelmente, variações em compostos orgânicos, consistência e fatores endógenos ocultos, os quais devem ter afetado a velocidade de emissão de brotações, de calo, de enraizamento e de desenvolvimento de folhas e folíolos. As estacas que brotaram e enraizaram primeiro tinham, provavelmente, maiores quantidades de reservas e de gemas diferenciadas, que induziram e aumentaram a velocidades de emissão de brotações e de desenvolvimento de folhas e folíolos.

Ressalta-se que aos 40 dias após o plantio das estacas, cerca de 50\% delas já tinham iniciado a diferenciação de gemas e a emissão de brotações, eventos que são fortes indicativos do possível enraizamento. Isso ocorre em razão das brotações passarem a sintetizar fotoassimilados e cofatores orgânicos que favorecem a formação de calo, a diferenciação de folíolos e a emissão de primórdios radiculares, conforme mencionam Hartmann et al. (2011).

Na Figura 4 observa-se o percentual de calos formados nas estacas de umbu-cajazeira. As estacas tratadas com Sela $\mathrm{Gel}^{\circledR}$ apresentaram as maiores percentagens de calo $(73,75 \%)$, mas foram estatisticamente iguais às tratadas com Radimax ${ }^{\circledR}$ $(67,50 \%)$ e superiores às estacas testemunhas $(53,75 \%)$. Não houve diferença estatística para estacas tratadas com Radimax ${ }^{\circledR} \mathrm{e}$ as estacas não tratadas. A formação de calo na base da estaca, seja induzida ou não por lesão, é importante para a iniciação radicular. A lesão estimula a divisão celular, eleva a absorção de água e de reguladores de crescimento, proporcionando aumento na formação de calo e, posteriormente, de raízes adventícias (Fachinello et al., 2005; Hartmann et al., 2011). Essas afirmações foram confirmadas neste experimento, observando-se a formação de calo e raízes a partir dos ferimentos feitos na base das estacas (Figura 5). Esses resultados confirmam que os ferimentos estimulam o enraizamento de estacas de ramo lenhoso de umbu-cajazeira. 
Figura 4. Percentagem de calo em estacas de umbu-cajazeira, aos 80 dias após o plantio. Pacajus, CE.

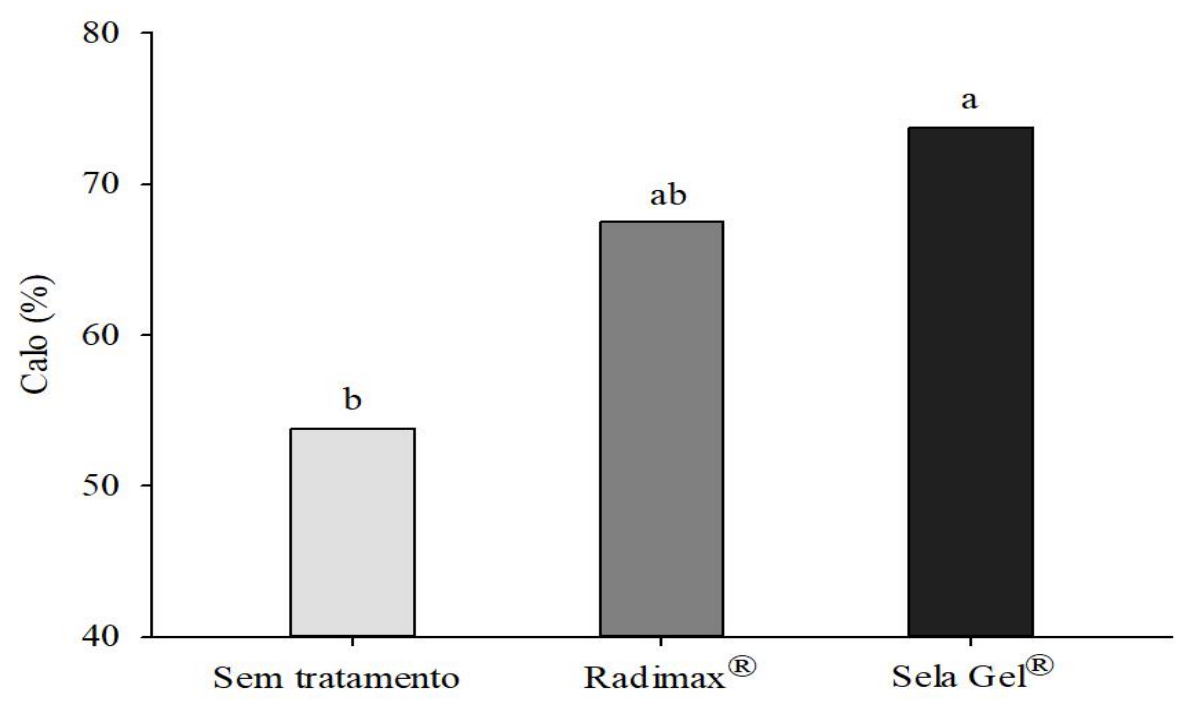

Fonte: Autores.

Figura 5. Estacas de propágulo lenhoso de umbu-cajazeira com brotações e folíolos, com calo, com e sem raízes a partir dos ferimentos na base das estacas, aos 80 dias após o plantio. Pacajus, CE.

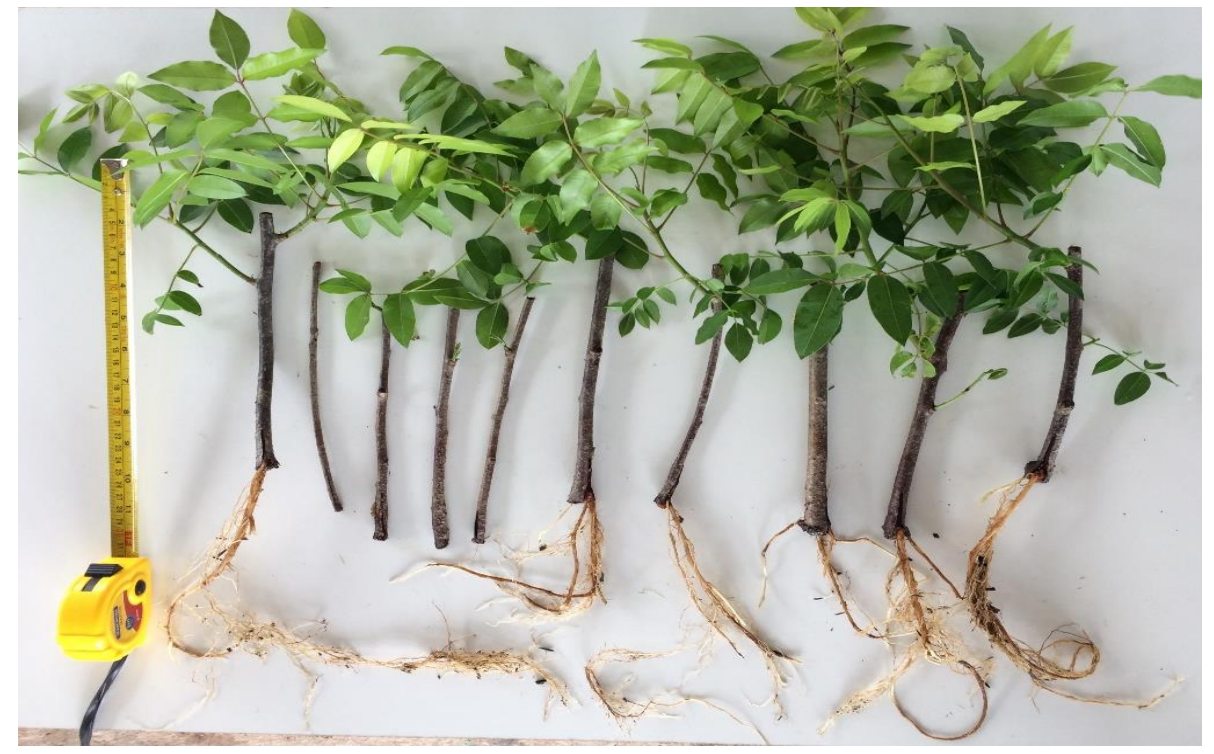

Fonte: Autores.

Na Figura 6 observa-se a percentagem de enraizamento de estacas de umbu-cajazeira. As estacas tratadas com Sela $\mathrm{Gel}^{\circledR}$ apresentaram as maiores percentagens de enraizamento $(51,25 \%)$, as quais diferiram estatisticamente das tratadas com $\operatorname{Radimax}^{\circledR}(22,50 \%)$ que, por sua vez, não diferiram das estacas não tratadas, que apresentaram apenas $13,75 \%$ de enraizamento. Os resultados obtidos com Sela Gel ${ }^{\circledR}$ foram muito superiores às taxas de enraizamento observadas por Vieira et al. (2020), com estacas de caule de umbu-cajazeira (20,74\% e 11,11\%), tratadas com ácido indolbutírico (AIB) a 1.000 mg.L-1 e a 3.000 mg. $\mathrm{L}^{-1}$ respectivamente. Já Bastos, Dantas, Costa, Bastos e Almeida (2014) obtiveram 35\% e Verás et al. (2018) 20,83\% de enraizamento nas estacas de umbu-cajazeira tratadas com 3.000 mg. $\mathrm{L}^{-1}$ de AIB; e Lima, Rezende, Câmara e Nunes (2002) obtiveram 52,68\% de enraizamento em estacas verdes de umbu-cajazeira. Mendes et al. (2019), utilizando Sela Gel ${ }^{\circledR}$ no enraizamento de umbu-cajazeira, alcançaram 68,75\% de enraizamento em estacas contendo ferimentos na base e $93,75 \%$ em estacas incisadas, resultados que foram bastante superiores aos registrados neste estudo. Entretanto, as estacas empregadas na 
pesquisa de Mendes et al. (2019) eram maiores (25 cm, com médias de 29,7 mm de diâmetro e 8,7 gemas por estaca) do que as utilizadas neste trabalho. O tamanho da estaca pode ser o fator que evidenciou a diferença entre os resultados, pois, sabe-se que as estacas de umbu-cajazeira possuem grandes reservas em seu interior.

Figura 6. Percentagem de enraizamento de estacas de umbu-cajazeira, aos 80 dias após o plantio. Pacajus, CE.

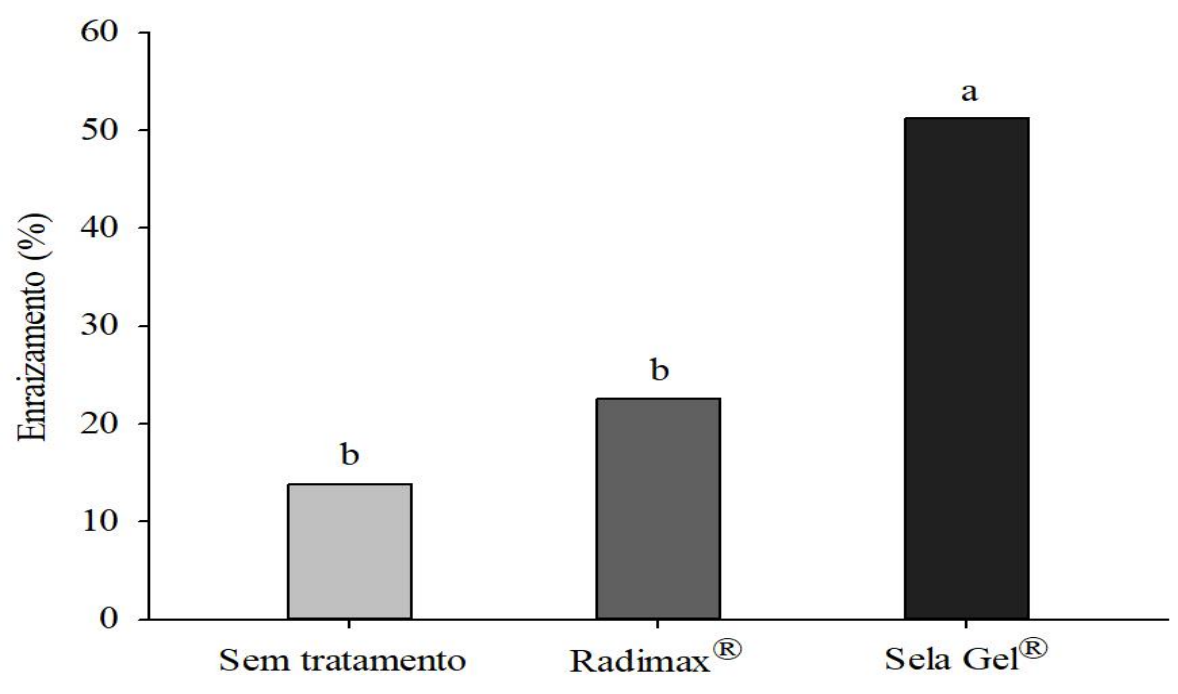

Fonte: Autores.

Na Figura 7 observa-se a percentagem de mudas aptas ao plantio formadas a partir de estacas de umbu-cajazeira. Estacas tratadas com Sela $\mathrm{Gel}^{\circledR}$ formaram mudas vigorosas e aptas ao plantio $(30,00 \%)$ no campo e diferiram das estacas tratadas com $\operatorname{Radimax}^{\circledR}(7,50 \%)$ e das que não foram tratadas $(8,75 \%)$, aos 80 dias depois do plantio nos vasos. Mendes et al. (2019), avaliando agroquímicos e lesões em estacas de caule na formação de mudas de umbu-cajazeira, observaram que a aplicação de Sela Gel ${ }^{\circledR}$ em conjunto com ferimento $(56,25 \%)$ ou incisão $(84,38 \%)$ na base das estacas, proporcionou médias superiores na formação de mudas aptas ao plantio. Notadamente, o uso do indutor de enraizamento Sela Gel ${ }^{\circledR}$ influenciou no desenvolvimento das mudas formadas por estaca de ramo lenhoso de umbu-cajazeira, o que pode ter sido proporcionado pela quantidade de AIB presente no produto, bem como pela proteção (formação de película) contra a formação da embolia após o corte e preparo das estacas. 
Figura 7. Percentagem de mudas aptas ao plantio formadas de estacas de umbu-cajazeira, aos 80 dias após o plantio. Pacajus, CE.

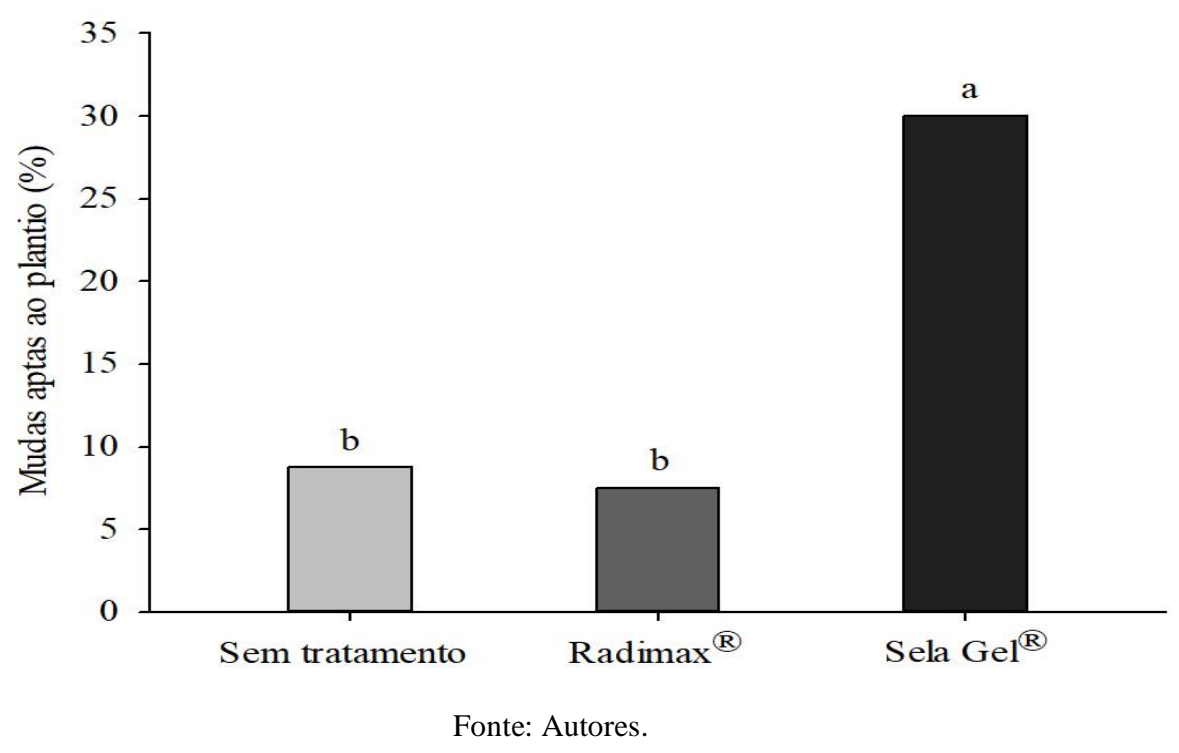

Nas Figuras 8 e 9 observa-se a quantidade de folíolos formados em mudas de estacas de umbu-cajazeira. As estacas tratadas com Sela Gel ${ }^{\circledR}$ alcançaram médias de 29,50 folíolos e tiverem médias superiores as tratadas com Radimax ${ }^{\circledR}(9,95)$, bem como das estacas que não receberam tratamento (10,08). Esse resultado foi inferior aos obtidos por Tosta et al. (2012), que obtiveram média de 38,4 folíolos com a dose de $4.218 \mathrm{mg} . \mathrm{L}^{-1}$ de AIB em estacas de umbu-cajazeira.

Figura 8. Número de folíolos em mudas provenientes de estacas de umbu-cajazeira, aos 80 dias após o plantio. Pacajus, CE.

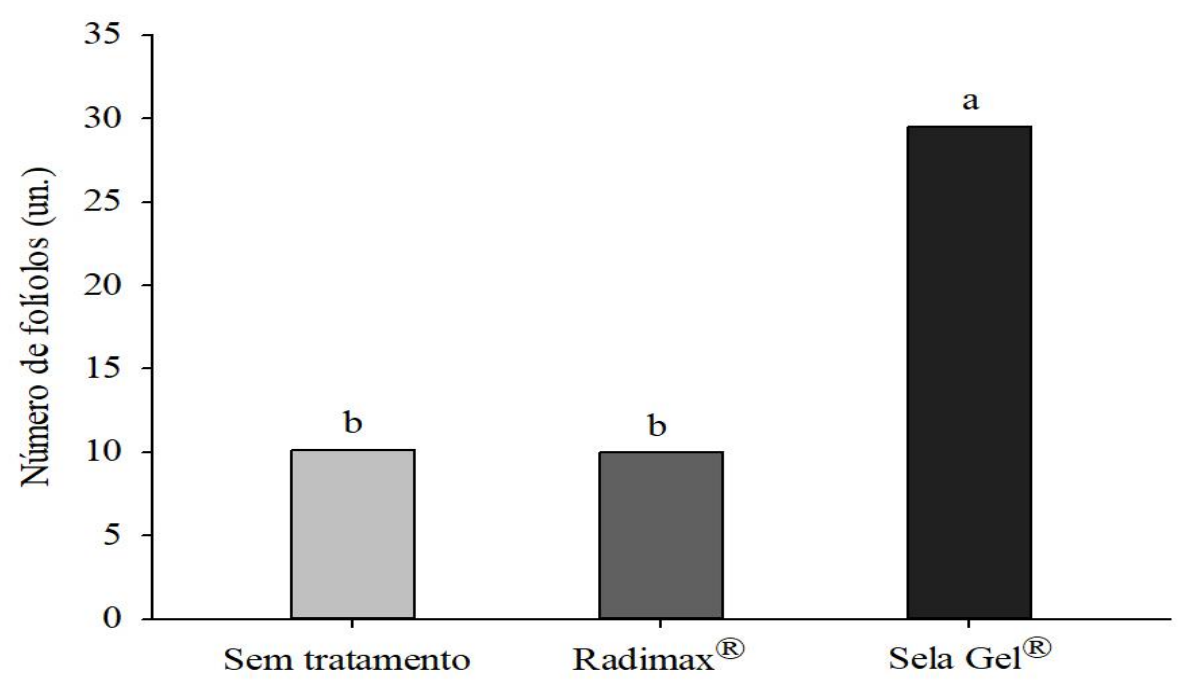

Fonte: Autores. 
Figura 9. Parcelas de estacas de propágulo lenhoso de umbu-cajazeira com folíolos e com folhas desenvolvidas e em desenvolvimento do tratamento com Sela $\mathrm{Gel}^{\circledR}$, aos 80 dias após o plantio. Pacajus, CE.

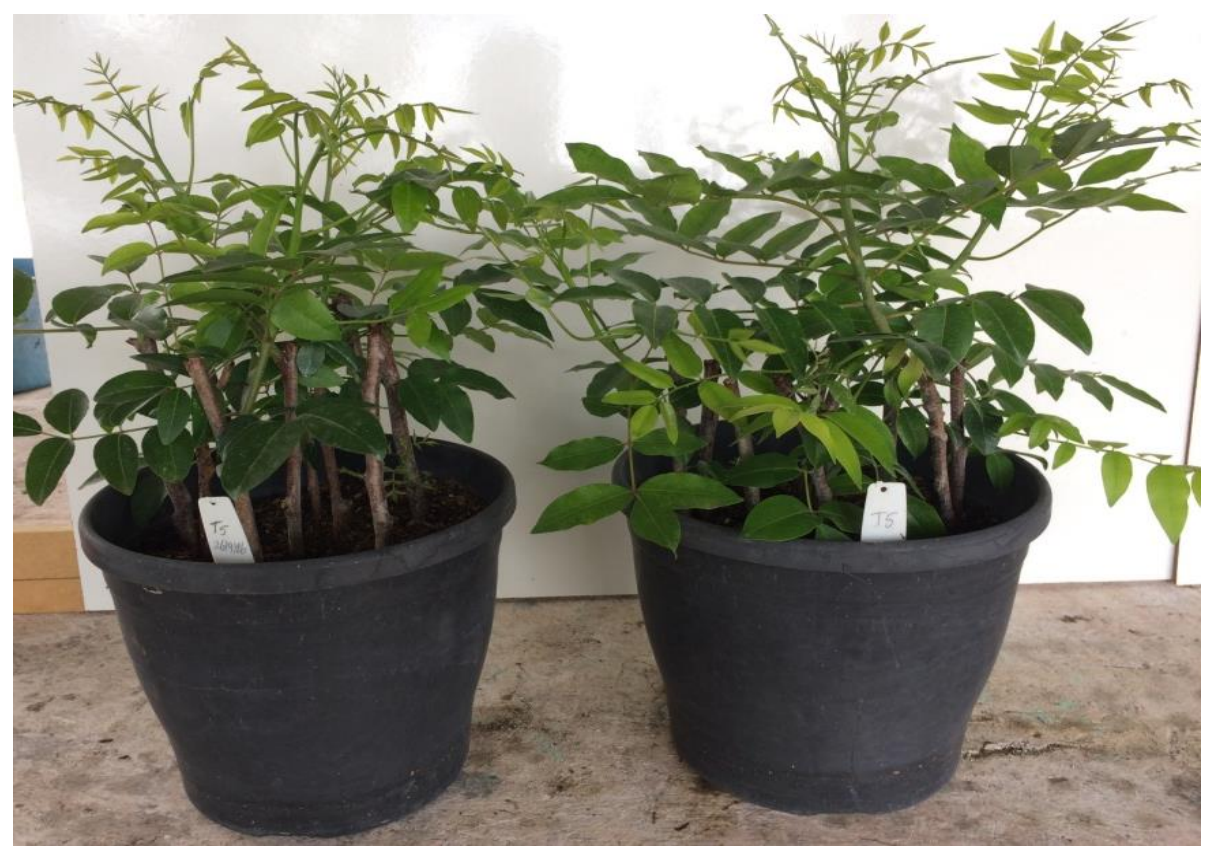

Fonte: Autores.

Com relação ao uso de estufim para a formação de mudas de umbu-cajazeira (Figura 10), as estacas desenvolvidas nos vasos com essa cobertura plástica apresentaram maior formação de calo nas suas bases (72,50\%), diferindo significativamente daquelas mantidas nos vasos sem estufim (57,50\%). Contudo, pôde-se observar nas visitas ao experimento que as estacas mantidas sob estufim apresentavam maior grau de umidade, pois a água da subirrigação não se perdia para o ambiente e, sim, permanecia dentro da estrutura. Na técnica de estaquia, a umidade deve ser sempre mantida, mesmo quando a estaca tiver o número de folhas reduzido para evitar excesso de perda de água por meio da transpiração e, consequentemente, a morte das células que estão em processo de divisão celular para o enraizamento (Hartmann et al., 2011).

Figura 10. Percentagem de calo em estacas de umbu-cajazeira formadas sob estufim, aos 80 dias após o plantio. Pacajus, CE.

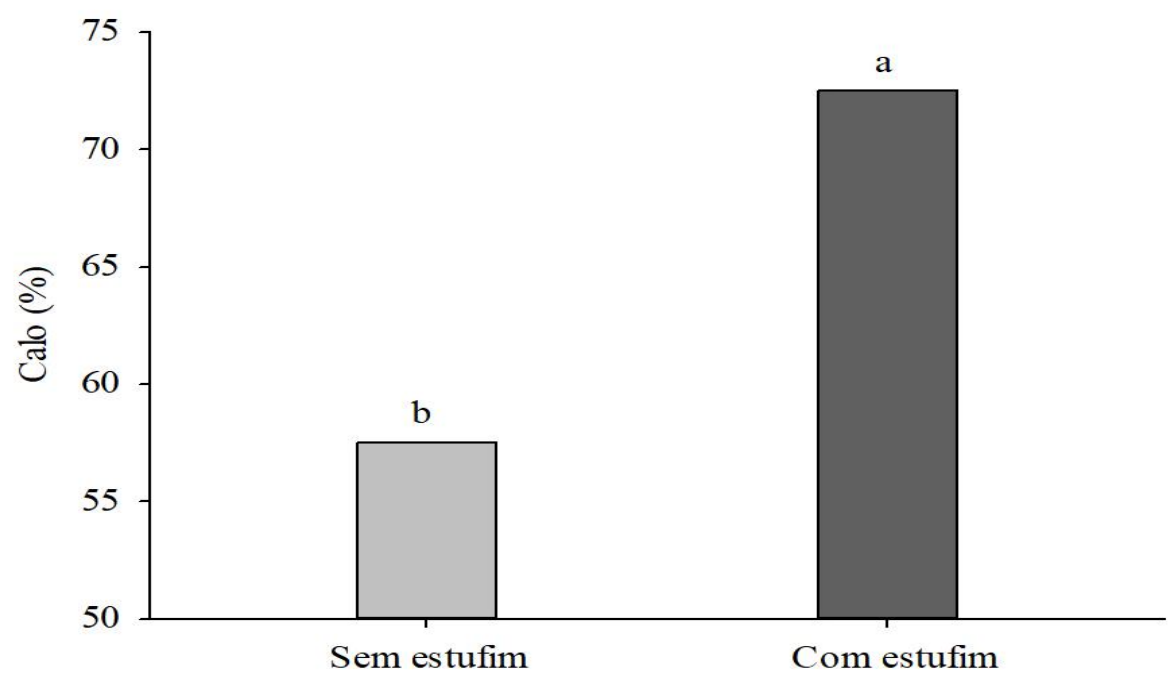

Fonte: Autores. 
Verificou-se, ainda, que havia muitas estacas contendo gemas brotadas, folíolos em diferenciação e calos formados fortemente induzido pelos ferimentos, mas sem presença de raízes adventícias. Esses resultados confirmam que as estacas emitem brotações e formam calo, mesmo antes da emissão de raízes adventícias, às expensas de suas reservas orgânicas. Observou-se que muitas estacas emitem, nas primeiras semanas após o plantio, panículas juntamente com as brotações, mesmo antes de enraizarem. Uma provável explicação para o referido evento é que as estacas foram formadas de propágulos lenhosos apicais, e que muitos destes já possuíam células dos meristemas determinadas do ponto de vista floral (Taiz \& Zeiger, 2013). A fim de que as mudas fossem formadas sem que houvesse atraso no seu desenvolvimento foram retiradas as panículas que surgiram.

No final do experimento, aos 80 dias após o plantio das estacas, foram avaliadas as 240 estacas e constatou-se que $81,25 \%$ delas tinham emitido brotações, $61,67 \%$ possuíam calo nos ferimentos basais, mas ainda não tinham enraizado. Estima-se que essas estacas enraizariam se o experimento tivesse sido conduzido por mais tempo; ou ainda, se o estufim fosse projetado sobre uma estrutura maior, de forma a não permitir o contato das estruturas vegetais com o plástico. A percentagem das estacas que não emitiram brotações, calos nem raízes e que morreram foi de 18,75\% do total.

\section{Considerações Finais}

Para a produção de mudas de propágulo lenhoso de umbu-cajazeira pela técnica de estaquia, recomenda-se o

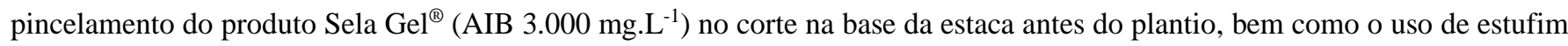
por aproximadamente 44 dias.

Em experimentos futuros devem-se pesquisar a utilização de outros indutores de enraizamento disponíveis no mercado e que sejam de fácil aplicabilidade, a utilização de propágulos de rebrota para testar sua eficiência na estaquia e, ainda, utilizar estruturas que promovam a modificação da característica do ambiente, por exemplo, os estufins com arquiteturas maiores do que as utilizadas nesse experimento.

\section{Agradecimentos}

Os autores agradecem à Universidade Federal do Ceará (UFC) e à Embrapa Agroindústria Tropical pelo apoio institucional e logístico, e à Coordenação de Aperfeiçoamento de Pessoal de Nível Superior (CAPES) pela concessão da bolsa ao primeiro autor.

\section{Referências}

Aguiar, M. J. N., Lima, J. B., Barreto Júnior, J. H. C., Carneiro, F. A., \& Lima, M. W. (2002). Dados climatológicos: Estação de Pacajus, 2001. (2002). Fortaleza, CE: Embrapa Agroindústria Tropical. 26 p. (Embrapa Agroindústria Tropical. Documentos, 60).

Barroso, M. M. A., Almeida, E. I. B., Corrêa, M. C. M., Cajazeira, J. P., Queiroz, R. F., \& Oliveira, I. M. S. (2017). Morfologia de propágulos e auxina exógena na estaquia de pitaia vermelha. Revista de Ciências Agrárias, 60(4), 350-357. doi.org/10.4322/rca.2608

Bastos, L. P., Dantas, A. C. V. L., Costa, M. A. P. C, Bastos, M. J. S. M., Almeida, V.O. (2014). Propagação vegetativa de umbu-cajazeira. Enciclopédia biosfera, 10(18), 2508-2517. https://conhecer.org.br/ojs/index.php/biosfera/article/view/2861

Bastos, L. P. (2010). Caracterização de frutos e propagação vegetativa de Spondias. 53 f. (Dissertação de mestrado em Ciências Agrárias). Universidade Federal do Recôncavo da Bahia - UFRB, Cruz das Almas, BA, Brasil.

Coda, 2016. http://www.coda-agri.com/pt/produtos/aminoacidos-ebiostimulants

Ecoplanet, 2012. http://www.ecoplanet.agr.br

Fachinello, J. C., Hoffmann, A., Nachtgal, J. C., \& Kersten, E. (2005). Propagação vegetativa por estaquia. In: Fachinello, J. C., Hoffmann, A., \& Nachtigal, J. C. (Ed.), Propagação de plantas frutíferas. (pp. 69-109). Brasília: EMBRAPA.

Hartmann, H. T., Kester, D. E., Davies Jr., F. T., \& Geneve, R. L. (2011). Plant propagation: principles and practices. (8th ed.). Prentice Hall, 915 p. 
Lima, A. K. C., Rezende, L. P., Câmara, F. A. A., \& Nunes, G. H. S. (2002). Propagação de cajarana (Spondias sp.) e cirigüela (Spondias purpurea) por meio de estacas verdes enfolhadas, nas condições climáticas de Mossoró-RN. Caatinga, 15(1/2), 33-38.

Lopes, W. F. (1997). Propagação assexuada de cajá (Spondias mombin L.) e cajá-umbu (Spondias spp.) através de estacas. 41 f. (Trabalho de conclusão de curso). Universidade Federal da Paraíba - UFPB, Areia, PB, Brasil.

Machado, M. C., Carvalho, P. C. L., \& Van den Berg, C. (2015). Domestication, hybridization, speciation, and the origins of an economically important tree crop of Spondias (Anacardiaceae) from the brazilian caatinga dry forest. Neodiversity, 8(1), 8-49. doi.org/10.13102/neod.81.2

Mendes, N. V. B., Souza, F. X., Rossetti, A. G., Natale, W., \& Corrêa, M. C. M. (2019). Agrochemicals and stem cutting types for plantlet production of Spondias sp. Revista Caatinga, 32(4), 1104-1110. doi.org/10.1590/1983-21252019v32n427rc

Mitchell, J. D., \& Daly, D. C. (2015). A revision of Spondias L. (Anacardiaceae) in the Neotropics. PhytoKeys, 55(1), 1-92. doi:10.3897/phytokeys.55.8489

Paiva, H. N., \& Gomes, J. M. (1995). Propagação vegetativa de espécies florestais. UFV, 40 p. (UFV, Boletim, 322).

Pereira, A. B., Aguilar, M. A. G., Sodré, G., Pasqual, M., \& Mendes, A. N. G. (2002). Enraizamento de estacas de Coffea arabica L. em estufim. Revista Agrotrópica, 14(3), 91-96. https://www.gov.br/agricultura/pt-br/assuntos/ceplac/publicacoes/revista-agrotropica/revista/agrotropica-2002v14n3.pdf/view

Pio, R., Ramos, J. D., Chalfun, N. N. J., Gontijo, T. C. A., Mendonça, V., Carrijo, E. P., \& Chagas, E. A. (2006). Propagação de estacas apicais de figueira: diferentes ambientes, ácido indolbutírico e tipo de estaca. Ciência e Agrotecnologia, 30(5), 1021-1026. doi.org/10.1590/S1413-70542006000500030

SAS INSTITUTE. (2008). SAS/STAT: user's Guide. Version 9.2. SAS Institute Inc.

Souza, F. X., Porto Filho, F. Q., \& Mendes, N. V. B. (2020). Umbu-cajazeira: descrição e técnicas de cultivo. Edufersa, 103 p. https://livraria.ufersa.edu.br/umbu-cajazeira-descricao-e-tecnicas-de-cultivo/

Souza, F. X., \& Costa, J. A. T. (2010). Produção de mudas das Spondias cajazeira, cirigueleira, umbu-cajazeira e umbuzeiro. Fortaleza: Embrapa Agroindústria Tropical. 26 p. (Embrapa Agroindústria Tropical. Documentos, 133). https://www.infoteca.cnptia.embrapa.br/bit stream/doc/883976/1/Doc133.pdf

Steel, R. G. D., \& Torrie, J. H. (1980). Principles and procedures of statistics: a biometrical approach. (2nd ed.). McGraw-Hill, 633 p.

Taiz, L., \& Zeiger, E. (2013). Fisiologia vegetal. (5a ed.). Artmed, 954 p.

Tosta, M. S., Oliveira, C. V. F., Freitas, R. M. O., Porto, V. C. N., Nogueira, N. W., \& Tosta, P. A. F. (2012). Ácido indolbutírico na propagação vegetativa de cajaraneira (Spondias sp.). Semina: Ciências Agrárias, 33(supl1), 2727-2740. doi:10.5433/1679-0359.2012v33Supl1p2727

Verás, M. L. M., Andrade, R., Figueredo, L. F., Araújo, V. L., Filho, J. S. M., Mendonça, R. M. N., \& Pereira, W. E. (2018). Uso de reguladores vegetais na propagação via estaquia de umbu-cajazeira. Revista de Ciências Agrárias, 41(3), 740-748. doi.org/10.19084/RCA17153

Vieira, A. R., Alves, R. E., Souza, F. X., Batista, M. A. V., \& Batista, I. M. V. (2020). Enraizamento de estacas de umbu-cajazeira tratadas com ácido indolbutírico. Brazilian Journal of Animal and Environmental Research, 3(4), 4134-4145. doi:10.34188/bjaerv3n4-109 